J. Lake Sci. (湖泊科学), 2011, 23(6): 982-990

http: //www.jlakes.org. E-mail : jlakes@niglas.ac.cn

(c) 2011 by Journal of Lake Sciences

\title{
太湖流域直湖港支流龙延河水系鱼类集群现状 *
}

王金庆, 宋祥甫**, 刘福兴, 邹国燕, 付子轼, 刘长娥, 刘娅琴, 潘 琦, 孙作登

( 上海市农业科学院,上海 201403)

\begin{abstract}
摘 要: 分别于 2009 年 8 月和 2010 年 5 月对直湖港支流龙延河水系的鱼类集群现状及其影响因素进行研究. 结果表明, 研究区域有多种鱼类存在,共采集到 31 种,隶属于 5 目 9 科 22 属; 春、夏两季鱼类集群的种类数没有明显差异, 但春季的 鱼类多度和生物量均显著高于夏季; 主干支流、次级支流和支流末端等不同区位的鱼类组成也有一定差异;水体透明度、 溶解氧与鲫、圆尾斗鱼、叉尾斗鱼多度显著正相关, 而氮、磷等营养盐浓度与似鳊、餐条、鲫鱼等种类的多度呈负相关; 水 体营养盐浓度过高及相应的溶解氧、透明度降低均对鱼类群落产生了不利影响.
\end{abstract}

关键词: 直湖港;龙延河;闸控入湖河流;鱼类集群;河道级别;水体污染;太湖流域

\section{Fish assemblage status in Longyanhe river system, tributary of Zhihugang, Taihu Basin}

WANG Jinqing, SONG Xiangfu, LIU Fuxing, ZOU Guoyan, FU Zishi, LIU Chang'e, LIU Yaqin, PAN Qi \& SUN Zuodeng

(Shanghai Academy of Agricultural Sciences, Shanghai 201403, P. R. China)

Abstract: In order to evaluate fish resource status in Zhihugang, gate-controlled inflow river of Lake Taihu, fish assemblage status in Longyanhe river system, main tributary of Zhihugang and their influencing factors were studied in August 2009 and May 2010 respectively. Results showed that a wide variety of fish species existed in the study area, and thirty two species of fish were collected, which belong to 22 genera, 27 families and 5 orders. Species numbers of fish assemblages in spring and summer had not obvious difference; however, fish abundance and biomass in spring were both significantly higher than those in summer; species composition of fish assemblages in different locations, that is, main tributary, secondary tributary and tributary end, varied as well. Water transparency and dissolved oxygen content were positively correlated with abundances of Carassius auratus, Macropodus ocellatus and Macropodus opercularis, Water nutrient concentrations, i. e., nitrogen and phosphorus, were negatively related to fish abundances of Pseudobrama simoni, Hemicculter leuciclus and Carassius auratus. Excess nutrient concentration and corresponding low water transparency and dissolved oxygen content produced an adverse effect on fish assemblage structure and species composition. Keywords: Zhihugang; Longyanhe; gate-controlled inflow river; fish assemblages; channel order; water pollution; Taihu Basin

太湖是我国著名的五大淡水湖泊之一, 自 1980s 起, 伴随着太湖流域经济社会的快速发展, 太湖湖体的 富营养化程度年趋加重, 对湖体的生态环境造成了较大破坏 ${ }^{[14]}$. 人湖河流的污染控制和水体生态修复是治 理太湖富营养化的重要途径, 而鱼类则能对河道的水环境污染做出快速响应, 有效反映河流水体污染状况.

直湖港是太湖最主要的 10 条人湖河流之一, 位于无锡市区西部, 北至江南运河, 西和西南与武进市相 邻, 东南与梅梁湾相接,东至钱桥, 流域内面积 $229.7 \mathrm{~km}^{2}$, 是无锡市惠山区和滨湖区重要的工业、农业基地. 本区域共有不同规格的河道 422 条, 总长 $411 \mathrm{~km}$, 蓄水量 $1.8 \times 10^{7} \mathrm{~m}^{3}$. 直湖港在其人太湖 (梅梁湾) 的河口已 建闸控制, 一般情况下, 其河水不进入梅梁湾, 但因其船闸长年运行, 有少量河水进入梅梁湾, 汛期为了泄洪 排涝,开闸时大量洪、涝水进入梅梁湾,总体呈现“缓流急排”的水文特征. 直湖港近几年的水质均劣于国家

* 国家水体污染控制与治理科技重大专项项目(2008ZX07101-005)和国家自然科学基金项目 (30821140542)联合 资助. 2011-01-07 收稿;2011-08-15 收修改稿. 王金庆, 男, 1980 年生, 博士, 助理研究员; E-mail: jinqwang@ 163. com.

** 通讯作者; E-mail: songxfu@ 263.net. 
地表水环境质量 $V$ 类标准 ( GB3838-2002), 主要超标污染物是氨氮、总氮和总磷. 据估计,2007 年通过直湖港 进人梅梁湾的化学需氧量、总氮和总磷分别达到了 $29160 、 3125$ 和 $103 \mathrm{t}$, 占整个太湖西岸人湖污染物的比例较 大. 当前, 区域内河道水体污染形势严峻, 加上当地渔民对鱼类资源的过度捕捞等因素, 直湖港水系的鱼类生 物多样性受到严重威胁. 鉴于上述现状,国家和地方政府对直湖港小流域开展了多项综合治理工程.

前人主要针对太湖湖区鱼类的群落特征、时空动态以及环境影响等几个方面进行了研究 ${ }^{[2-5]}$, 但对于水 体污染程度较重的河流,尤其是分布于居民区小水系的鱼类集群开展的研究工作很少. 本研究通过对直湖 港水系典型村域范围的系统取样 (从盲肠小河道至各级支流), 采用典型对应分析方法, 探讨污染严重河流 内的鱼类集群现状,分析鱼类集群与环境变量的关系, 旨在为人湖河流直湖港的水体污染控制和生态修复 提供参考资料.

\section{1 材料与方法}

\section{1 取样位置}

为了全面评价直湖港水系鱼类资源的现状与变化, 同时考虑到取样点的典型性和系统性, 在反复调研、 比选的基础上,分别于 2009 年 8 月和 2010 年 5 月对位于直湖港下游,无锡市胡埭镇龙延河水系主要河道的 鱼类进行取样. 每次取样持续 $3 \mathrm{~d}$, 大多数时间天气晴朗, 取样具有代表性. 在直湖港支流龙延河水系 $\left(31^{\circ} 31^{\prime}\right.$ $43^{\prime \prime}-31^{\circ} 32^{\prime} 14^{\prime \prime} \mathrm{N}, 120^{\circ} 6^{\prime} 9^{\prime \prime}-120^{\circ} 6^{\prime} 35^{\prime \prime} \mathrm{E}$ ) 共设置了 9 个样点 (图 1). 取样点遍及该区域上下游以及村落的各 级支流 (包括育肠河道),包括龙延河、下场浜、淀溪环浜、王典桥浜、是家旦浜、白水塘浜等 6 个分支,基本代 表了直湖港小流域的水系格局, 能基本完整反映该区域的水文特征. 相邻样点间距介于 $90-300 \mathrm{~m}$, 平均为 $222.7 \pm 37.7 \mathrm{~m} .2009$ 年 8 月、2010 年 5 月河流平均水深分别为 $275 \mathrm{~cm} 、 189 \mathrm{~cm}$, 河流水位主要受到上游来 水、降雨和地表径流的影响.

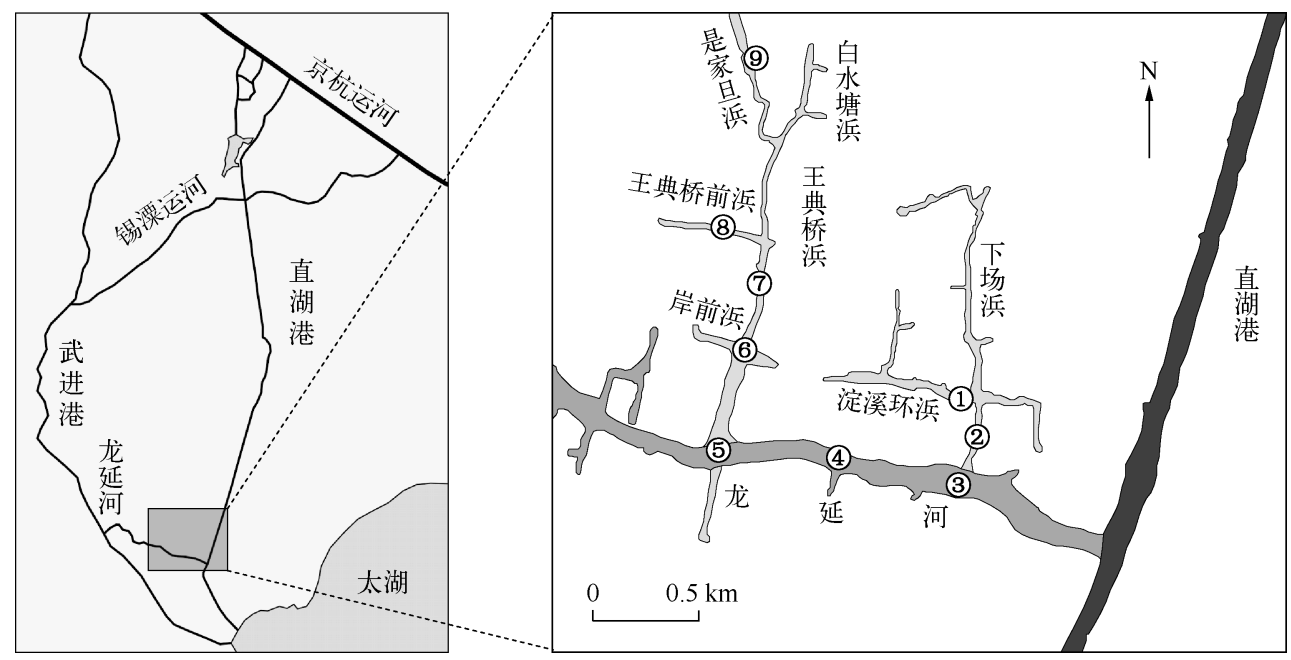

图 1 龙延河水系鱼类取样点位置分布示意

Fig. 1 Fish sampling sites in Longyanhe river system

\section{2 鱼类取样}

本研究采用刺网和地笼相组合的方法采集鱼类样品 (图 2). 其中刺网包括大浮刺网、小浮刺网、大沉刺 网和小沉刺网四种, 网具的长度均为 $25 \mathrm{~m}$, 小浮刺网、沉刺网的孔径均为 $3 \mathrm{~cm}$, 为单层刺网, 大浮刺网、沉刺 网的孔径均为 $10 \mathrm{~cm}$, 为三层刺网. 同时采用地笼补充取样底栖鱼类, 地笼长度为 $5 \mathrm{~m}$, 直径 $25 \mathrm{~cm}$, 网布孔径 为 $1 \mathrm{~cm}$. 鱼类多度, 即取样点的鱼类个体数, 用单位时间捕获努力渔获量 (Catch Per Unit Effort, CPUE) 表示, 四种刺网均在河道里放置 $2 \mathrm{~h}$ 后收起, 地笼在河道底部放置 $1 \mathrm{~d}$ 后收起, 将刺网、地笼采集的所有样品合并, 作为样点每次取样的捕获量. 各样点取样在白天 9:00 至 $15: 00$ 期间连续进行,在河道中央撒网. 河道水深在 


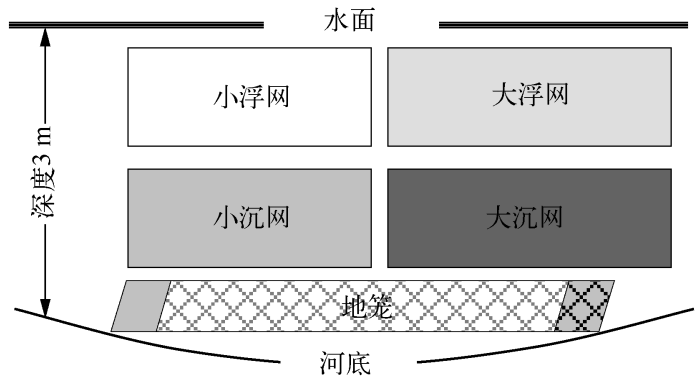

图 2 龙延河河道内渔具设置示意

Fig. 2 Schematic diagram of deploying fish nets in Longyanhe
2-3 $\mathrm{m}$ 的范围, 浮网占据水体上层, 沉网占据 下层, 地笼位于底层, 小浮刺网、沉刺网高度为 $1 \mathrm{~m}$, 大浮刺网、沉刺网高度 $1.5 \mathrm{~m}$. 四种网具同 时取样能覆盖河道 2-3 $\mathrm{m}$ 的水深, 因而刺网能 对各个水层的鱼类进行较全面取样, 能如实反 映龙延河水系鱼类群落的状况. 采集鱼类样品 后, 用 $8 \%$ 的甲醛溶液保存样品, 带回实验室鉴 定种类, 并测量鱼的全长、体重、生物量, 统计 种类数和个体数. 图 2 为刺网和地笼布置与相 对水深示意图.

\section{3 水质测定}

同步测定的水体理化指标包括总氮 $(T N)$ 、总磷 $(T P)$ 、氨氮 $\left(N_{3}-N\right)$ 、高锰酸盐指

数 $\left(\mathrm{COD}_{\mathrm{Mn}}\right)$ 、透明度 $(\mathrm{SD})$ 、溶解氧 $(\mathrm{DO})$ 、水深 $(\mathrm{WDP})$ 、河道宽度 $(\mathrm{RW})$ 共 8 项. 用直径为 $30 \mathrm{~cm}$ 塞氏盘测定 水体 SD, 使用便携式溶氧仪 (Sentry M-2, Myratek, USA) 测定水体 20-150 cm 深处 DO 含量, WDP 和 RW 用 米尺测量. TN 的测定方法为碱性过硫酸钾氧化紫外分光光度法, $\mathrm{TP}$ 为锄锑抗分光光度法, $\mathrm{NH}_{3}-\mathrm{N}$ 为纳氏试 剂比色法, $\mathrm{COD}_{\mathrm{Mn}}$ 采用酸性高锰酸钾法测定 ${ }^{[6]}$.

\section{4 数据分析}

采用典型对应分析 (Canonical Correspondence Analysis, CCA) 研究鱼类集群特征与环境变量间的相互关 系. CCA 分析包括鱼类物种多度和环境变量两个数据库, 环境数据库包含取样季节、 $\mathrm{TN} 、 \mathrm{TP} 、 \mathrm{NH}_{3}-\mathrm{N} 、 \mathrm{COD}_{\mathrm{Mn}}$ 、 SD、DO、WDP、RW 共 9 个指标; 物种矩阵是物种的多度, 共包括 31 个鱼类物种. 分析步骤参照刘叔德等的分 析方法 ${ }^{[7]}$, 分析前对物种数据进行对数转换. 采用成对 $\mathrm{t}$ 检验分析两次取样间环境变量的差异, 而对物种多 度与水质指标进行 Pearson 相关性分析. 文中出现的数值 $X \pm Y$ 均表示平均值 \pm 标准误. CCA 分析采用 Canoco 4.5 ,统计检验采用 Statistica 7.0 完成.

\section{2 结果}

\section{1 物种总体分布概况}

本研究采集的鱼类隶属于 5 目 9 科 22 属 31 种. 其中, 鲤形目 (Cypriniformes) 包含 22 种、鲇形目 (Perciformes) 5 种、鲱形目 (Clupeiformes) 2 种、鲇形目 (Siluriformes) 1 种、合鳃鱼目 (Synbranchiformes) 1 种. 以其中 的似鲑多度最高, 共 593 尾, 鲤的生物量最高, 共 $7835.8 \mathrm{~g}$. 捕获物中以鲤科鱼类为主, 占总量的 $90 \%$ 以上 (表 1). CCA 分析表明,第一、二轴的特征值分别为 $0.480 、 0.222$, 共解释种类变异的 $37.5 \%$ 和环境变异的 $55.2 \%$, Monte-Carlo 检验结果表明, 直湖港水系鱼类集群与河道水环境因子具有显著的关系 (图 $3 \mathrm{a}, P<$ $0.05)$. 从各影响因素的边缘效应来看, 2009 年夏季和 2010 年春季鱼类的物种组成发生了明显改变, 主干支 流、次级支流和支流末端等不同位置的鱼类组成也存在明显的差异, 而且 $\mathrm{COD}_{\mathrm{Mn}}$ 、水深对鱼类集群也表现出 较大影响 (表 2).

\section{2 季节更替对鱼类集群的影响}

2009 年夏和 2010 年春的水体理化指标不尽相同 (表 3). 在 2009 年夏接近丰水期, 2010 年春接近枯水 期的前提下,鱼类生存相对敏感的 $\mathrm{COD}_{\mathrm{Mn}} 、 \mathrm{NH}_{3}-\mathrm{N}$ 和 $\mathrm{DO}$ 等主要理化指标, 2010 年 5 月显著优于 2009 年 8 月,这表明 2010 年 5 月的鱼类生存条件优于 2009 年 8 月. 鱼类多度数据表明, 2009 年 8 月捕获鱼类 355 尾, 重 $9722.6 \mathrm{~g}$, 共 21 种, 而 2010 年 5 月多度显著增加, 捕获 1234 尾, 重 $13995.4 \mathrm{~g}$, 共 22 种. 而且,2010 年不但 有多种鱼类的多度和生物量远高于 2009 年, 且种类也有一定程度的增加, 例如似鳊、高体鳑鲏、麦穗鱼、子 陵吻虾虎鱼的多度在 2009 年分别为 4、31、38、5 尾,2010 年则增至 589、148、123、98 尾; 似鳊、餐条、鲫的生物 量 2010 年分别为 $2941.1 、 3185.8 、 916.0 \mathrm{~g}$, 明显高于 2009 年的 $32.0 、 1300.0 、 685.2 \mathrm{~g}$; 刀鲚、黄鳝、攰嘴鲌、乌 鳢等 8 个种类只在 2009 年采集到,而鳙,黄颞鱼,草鱼,泥鱾, 大鯺刺鳑鲏等 10 个种类仅在 2010 年采集到. 但上述结果是否与当时的水质状况直接相关, 仍有待于可控条件下的实验研究进一步予以验证. 
表 $12009-2010$ 年龙延河水系鱼类物种总结和 CCA 分析得分

Tab. 1 Summary data and canonical correspondence analysis scores for fish species in Longyanhe river system from 2009 to 2010

\begin{tabular}{|c|c|c|c|c|c|c|}
\hline \multirow{2}{*}{ 种名 } & \multirow{2}{*}{ 代码 } & \multirow{2}{*}{ 平均全长 $(\mathrm{cm})$} & \multirow{2}{*}{ 多度 } & \multirow{2}{*}{ 生物量 $(\mathrm{g})$} & \multicolumn{2}{|c|}{ CCA 得分 } \\
\hline & & & & & 轴 1 & 轴 2 \\
\hline 似鳊 Pseudobrama simoni & $a$ & 8.6 & 593 & 2973.1 & -0.61 & 0.26 \\
\hline 餐条 Hemicculter leuciclus & $b$ & 13.0 & 217 & 4485.8 & 0.23 & 0.03 \\
\hline 高体鳑鲏 Rhodeus ocellatus & $c$ & 4.6 & 179 & 214.4 & -0.23 & -0.25 \\
\hline 麦穗鱼 Pseudorasbora parva & $d$ & 7.2 & 161 & 585.4 & -0.40 & -0.15 \\
\hline 子陵吻虾虎鱼 Rhinogobius giurinus & $e$ & 5.3 & 103 & 213.8 & -0.53 & -0.01 \\
\hline 鲫 Carassius auratus & $f$ & 9.7 & 92 & 1601.2 & 0.91 & 0.34 \\
\hline 贝氏餐 Hemicculter bleekeri & $g$ & 12.4 & 62 & 989.4 & 1.36 & 0.06 \\
\hline 彩石鲋 Pseudoperilampus lighti & $h$ & 4.5 & 57 & 62.1 & -0.79 & 0.21 \\
\hline 大鯺刺鳑鲏 Acanthorhodeus macropterus & $i$ & 6.0 & 37 & 106.8 & -0.86 & 0.10 \\
\hline 刀鲚 Coilia nasus & $j$ & 12.6 & 13 & 38.8 & 0.72 & -1.93 \\
\hline 鲤 Cyprinus carpio & $k$ & 33.5 & 13 & 7835.8 & 1.13 & -0.13 \\
\hline 鳙Aristichihys nobilis & $l$ & 27.9 & 11 & 2703.4 & -0.27 & 0.10 \\
\hline 圆尾斗鱼 Macropodus ocellatus & $m$ & 5.9 & 11 & 34.2 & 0.60 & 0.74 \\
\hline 黄鳝 Monopterus albus & $n$ & 37.5 & 5 & 234.2 & 2.06 & 2.01 \\
\hline 黄尾鲖 Xenocypris davidi & $o$ & 6.0 & 5 & 10.2 & 0.28 & -1.45 \\
\hline 棒花鱼 Abbottina rivularis & $p$ & 6.8 & 3 & 13.9 & 0.18 & -0.33 \\
\hline 鳊 Parabramis pekinensis & $q$ & 18.9 & 3 & 305.1 & 0.92 & 0.01 \\
\hline 短领鲚 Coilia brachygnathus & $r$ & 8.4 & 3 & 4.9 & 0.87 & -2.02 \\
\hline 红鯺原鲌 Cultrichthys erythropterus & $s$ & 14.4 & 3 & 222.7 & -0.09 & 0.22 \\
\hline 黄颡鱼 Pelteobagrus fulvidraco & $t$ & 12.0 & 3 & 340.1 & -0.49 & 0.16 \\
\hline 翅嘴鲌 Culter alburnus & $u$ & 6.5 & 3 & 7.0 & 0.72 & -2.10 \\
\hline 草鱼 Ctenopharyn odon idellus & $v$ & 29.7 & 2 & 659.8 & -0.27 & 0.10 \\
\hline 中华刺鲀 Sinobdella sinensis & $w$ & 14.8 & 2 & 18.2 & -1.10 & -0.15 \\
\hline 叉尾斗鱼 Macropodus opercularis & $x$ & 5.5 & 1 & 2.0 & 1.65 & 0.63 \\
\hline 达氏鲌 Culter dabryi & $y$ & 10.4 & 1 & 10.2 & -0.27 & 0.10 \\
\hline 亮银鲍 Squalidus nitens & $z$ & 8.8 & 1 & 5.5 & -0.79 & 0.55 \\
\hline 蒙古鲌 Culter mongolicus & $a l$ & 6.1 & 1 & 1.9 & 0.87 & -2.02 \\
\hline 泥䱊 Misgurnus anguilicaudatus & $b l$ & 13.0 & 1 & 12.1 & -0.79 & 0.55 \\
\hline 乌鳢 Ophicephalus argus & $c l$ & 11.1 & 1 & 13.4 & 1.19 & 0.28 \\
\hline 细鳞鲖 Xenocyprinae microlepis & $d l$ & 8.5 & 1 & 5.2 & -0.65 & -0.06 \\
\hline 银鲖 Xenocypris argentea & el & 9.0 & 1 & 7.5 & 1.36 & -0.70 \\
\hline
\end{tabular}

$\mathrm{CCA}$ 分析表明, 第一轴 (横轴) 与季节相关性最大, 与 $\mathrm{COD}_{\mathrm{Mn}}$ 呈较大正相关, 与水体 TP 浓度呈负相关, 排 序图横轴从左向右代表了 $\mathrm{COD}_{\mathrm{Mn}}$ 逐渐增加和 $\mathrm{TP}$ 浓度逐渐降低的变化趋势 (图 3a). 沿第一轴从原点向左表 示, 2010 年春季的水体 $\mathrm{COD}_{\mathrm{Mn}}$ 和 $\mathrm{TN}$ 浓度较低、TP 较高, 分布的主要鱼类是似鳊 $(a)$ 、高体鳑鲔 $(c)$ 、麦穗鱼 $(d)$ 、子陵吻虾虎鱼 $(e)$ 、彩石鲋 $(h)$ 、大鳍刺鳑鲔 $(i)$ 、中华刺䱊 $(w)$ 等; 从原点向右表示, 2009 年夏季的水体 $\mathrm{COD}_{\mathrm{Mn}}$ 及 $\mathrm{TN}$ 浓度较高、TP 较低, 分布的鱼类主要包括鲫 $(f)$ 、贝氏餐 $(g)$ 、刀鲚 $(j)$ 、鲤 $(k)$ 、黄鳒 $(n)$ 、黄尾鲖 $(o)$ 、鳊 $(q)$ 、短领鲚 $(r)$ 、趐嘴鲌 $(u)$ 、叉尾斗鱼 $(x)$ 、乌鳢 $(c l)$ 、银鲖 $(e l)$ 等. 

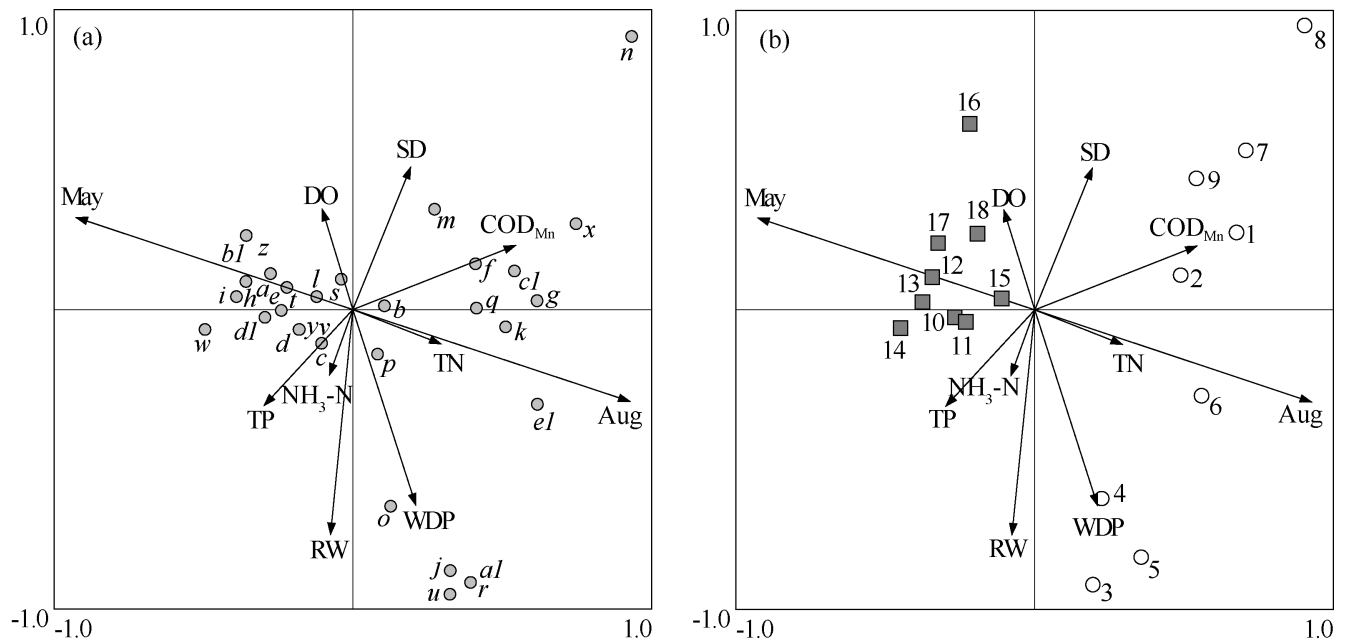

图 3 龙延河水系鱼类与环境的 CCA 二维排序图: (a) 物种与环境变量, (b) 样点与环境变量

( ○表示 2009 年 8 月样点, 口表示 2010 年 5 月样点,物种和环境变量缩写的解释见 表 1 和表 2 ,原点代表环境变量平均值)

Fig. 3 CCA biplots of fish assemblages and environmental variables in Longyanhe river system:

(a) species and environmental variables, (b) sampling stations and environmental variables

表 $22009-2010$ 年环境变量的显著性检验及其 CCA 各轴的相关系数

Tab. 2 Testing significances of environmental variables and their correlation coefficients with CCA axis during $2009-2010$

\begin{tabular}{lccccrrr}
\hline \multirow{2}{*}{ 环境变量 } & 代码 & 边缘效应 & $F$ & $P$ & \multicolumn{2}{c}{ 相关系数 } \\
\cline { 5 - 7 } & & & & & \multicolumn{1}{c}{ 轴 1} & 轴 2 \\
\hline 月 & $\mathrm{May}$ & 0.44 & 4.89 & 0.002 & -0.9173 & 0.2676 \\
8 月 & $\mathrm{Aug}$ & 0.44 & 4.89 & 0.002 & 0.9173 & -0.2676 \\
高锰酸盐指数 & $\mathrm{COD}_{\mathrm{Mn}}$ & 0.19 & 1.03 & 0.378 & 0.5377 & 0.1861 \\
河道宽度 & $\mathrm{RW}$ & 0.17 & 2.17 & 0.004 & -0.0748 & -0.6533 \\
水深 & $\mathrm{WDP}$ & 0.16 & 1.23 & 0.244 & 0.2080 & -0.5680 \\
透明度 & $\mathrm{SD}$ & 0.14 & 1.43 & 0.14 & 0.1911 & 0.4121 \\
总氮 & $\mathrm{TN}$ & 0.13 & 1.16 & 0.278 & 0.2900 & -0.0997 \\
总磷 & $\mathrm{TP}$ & 0.13 & 1.33 & 0.192 & -0.2934 & -0.2787 \\
溶解氧 & $\mathrm{DO}$ & 0.10 & 1.36 & 0.222 & -0.1017 & 0.2897 \\
氨氮 & $\mathrm{NH}-\mathrm{N}$ & 0.10 & 0.86 & 0.51 & -0.0780 & -0.1898 \\
\hline
\end{tabular}

表 32009 年 8 月与 2010 年 5 月环境变量的成对 $t$ 检验 $*$

Tab. 3 Testing the differences of environmental variables by paired $t$-test between samples collecting in August 2009 and May 2010

\begin{tabular}{|c|c|c|c|c|}
\hline 环境变量 & 2009 年 8 月 & 2010 年 5 月 & $t$ & $P$ \\
\hline $\mathrm{TN}(\mathrm{mg} / \mathrm{L})$ & $4.66 \pm 0.25$ & $3.94 \pm 0.20$ & 2.29 & 0.036 \\
\hline $\mathrm{TP}(\mathrm{mg} / \mathrm{L})$ & $0.24 \pm 0.02$ & $0.25 \pm 0.03$ & -0.46 & 0.653 \\
\hline $\mathrm{NH}_{3}-\mathrm{N}(\mathrm{mg} / \mathrm{L})$ & $1.36 \pm 0.11$ & $1.20 \pm 0.25$ & 0.62 & 0.544 \\
\hline $\mathrm{COD}_{\mathrm{Mn}}(\mathrm{mg} / \mathrm{L})$ & $7.45 \pm 0.64$ & $5.97 \pm 0.37$ & 2.22 & 0.041 \\
\hline $\mathrm{SD}(\mathrm{cm})$ & $54.1 \pm 11.30$ & $57.40 \pm 5.00$ & -0.27 & 0.791 \\
\hline $\mathrm{DO}(\mathrm{mg} / \mathrm{L})$ & $5.03 \pm 0.23$ & $5.96 \pm 0.58$ & -1.50 & 0.154 \\
\hline $\mathrm{WDP}(\mathrm{cm})$ & $274.90 \pm 31.00$ & $189.20 \pm 23.30$ & 2.21 & 0.042 \\
\hline
\end{tabular}

* 表中数值表示为平均值 \pm 标准误, $d f=16$. 


\section{3 其他环境因子对鱼类集群的影响}

图 3b 指示了样点间环境因子的差异,2009 年样点在纵轴上比较分散,样点间透明度、河道宽度和水深 等差异较大, 2010 年样点相对集中, 透明度、水深差异较小. 通过对 9 个样点的水质及鱼类特征比较表明, $3^{\#} 、 4^{\#} 、 5^{\#}$ 样点位于龙延河上, 其 $\mathrm{TN}(4.54 \mathrm{mg} / \mathrm{L}) 、 \mathrm{TP}(0.31 \mathrm{mg} / \mathrm{L}) 、 \mathrm{NH}_{3}-\mathrm{N}(1.75 \mathrm{mg} / \mathrm{L})$ 浓度相对较高, 透明度 $(35.3 \mathrm{~cm}) 、 \mathrm{DO}(4.44 \mathrm{mg} / \mathrm{L})$ 低, 综合水质在研究区域内最差, 而鱼类总多度是研究区域内最高的 $(210 \pm 41$ 尾), 高体鳑鲏 $(33 \pm 6$ 尾)、大鯺刺鳑鲏 ( $11 \pm 4$ 尾)、彩石鲋 ( $13 \pm 3$ 尾)、麦穗鱼 ( $32 \pm 10$ 尾)、子陵吻虾虎鱼 (21 \pm 9 尾) 等种类在该区的多度较高, 刀鲚、短领鲚、趐嘴鲌、黄尾鲖只在龙延河分布. $1^{\#} 、 2^{\#}$ 样点是位于研究 区域东侧的支流下场浜, 其水体透明度最高 $(85.4 \mathrm{~cm})$, DO 含量居中 $(5.31 \mathrm{mg} / \mathrm{L}), \mathrm{TN}(3.66 \mathrm{mg} / \mathrm{L}) 、 \mathrm{NH}_{3}-\mathrm{N}$ $(0.61 \mathrm{mg} / \mathrm{L})$ 和 $\mathrm{TP}(0.17 \mathrm{mg} / \mathrm{L})$ 浓度最低, 综合水质在研究区域内最好, 但鱼类总多度均值 $(201 \pm 19$ 尾) 却 略低于龙延河样点; 西侧支流的 $6^{\#} 、 7^{\#} 、 8^{\#}$ 样点位于岸前浜、王典桥前浜、王典桥浜, 其水体透明度 $(54.2 \mathrm{~cm})$ 、 $\mathrm{DO}(5.97 \mathrm{mg} / \mathrm{L})$ 较高, $\mathrm{TN}(4.16 \mathrm{mg} / \mathrm{L}) 、 \mathrm{NH}_{3}-\mathrm{N}(1.09 \mathrm{mg} / \mathrm{L}) 、 \mathrm{TP}(0.20 \mathrm{mg} / \mathrm{L})$ 浓度较低, $\mathrm{COD}_{\mathrm{Mn}}(6.65 \mathrm{mg} / \mathrm{L})$ 居中,综合水质仅次于下场浜,而鱼类平均多度 $(157 \pm 28$ 尾) 甚至低于下场浜; 次级支流的鱼类以餐条、似 鳊、鲫鱼多度较高. 支流最末端 9 号样点位于是家旦浜,其水体 DO 含量最高 $(7.7 \mathrm{mg} / \mathrm{L})$, 但 TN $(5.28 \mathrm{mg} / \mathrm{L}) 、$ $\mathrm{TP}(0.30 \mathrm{mg} / \mathrm{L}) 、 \mathrm{NH}_{3}-\mathrm{N}(1.77 \mathrm{mg} / \mathrm{L})$ 和 $\mathrm{COD}_{\mathrm{Mn}}(10.21 \mathrm{mg} / \mathrm{L})$ 也是区域中最高的, 综合水质较差, 相应鱼类总 多度最低 ( 86 尾), 仅圆尾斗鱼 ( 7 尾)、麦穗鱼 ( 16 尾) 多度较高.

CCA 排序图中 (图 3a), 第二轴 (纵轴) 与透明度呈正相关性, 与河道宽度、水深呈较大的负相关性, 排序 图下方表示, 在河道宽度大、水体的 $\mathrm{NH}_{3}-\mathrm{N}$ 、TP 含量高、水质差的位置,典型物种是刀鲚 $(j)$ 、短领鲚 $(r)$ 、趐嘴 鲌 $(u)$ 、黄尾鲖 $(o)$, 排序图上方表示在河道窄浅、透明度和 DO 高、水质好的位置, 鱼类以圆尾斗鱼 $(m)$ 、叉 尾斗鱼 $(x)$ 、泥鲉 $(b l)$ 、黄鳝 $(n)$ 、鲫 $(f)$ 为主. 通过 CCA 分析与上述各样点具体数据的比较, 得到一致的结 论,相关分析也印证了河道宽度、水深对鱼类集群的影响 (表 4), 水深与趐嘴鲌多度、河道宽度与刀鲚、黄尾 鲖、趐嘴鲌的多度均呈正相关关系, 而透明度与鲫、圆尾斗鱼、叉尾斗鱼的多度、DO 与圆尾斗鱼多度也呈正 相关性. TN 浓度与似鳊、餐条的多度、COD $\mathrm{Mn}_{\mathrm{n}}$ 与鱼类总多度、子陵吻虾虎鱼多度, TP 浓度与鲫多度均呈显著 的负相关关系. 水体营养盐浓度增高对鱼类大多具有负面的影响.

表 $42009-2010$ 年龙延河水系鱼类多度与环境变量的 Pearson 相关系数 ${ }^{1)}$

Tab. 4 Coefficients of Pearson's correlations between fish abundances and environmental variables in Longyanhe river system in $2009-2010$

\begin{tabular}{|c|c|c|c|c|c|c|c|c|c|c|}
\hline \multirow{2}{*}{ 环境变量 } & \multirow{2}{*}{ 总多度 } & \multicolumn{9}{|c|}{ 物种多度 } \\
\hline & & $a$ & $b$ & $e$ & $f$ & $j$ & $m$ & $o$ & $u$ & $x$ \\
\hline $\mathrm{TN}$ & -0.46 & $-0.51^{*}$ & $-0.56^{*}$ & -0.11 & 0.00 & 0.08 & -0.06 & 0.09 & 0.10 & -0.22 \\
\hline TP & 0.11 & -0.01 & -0.23 & 0.24 & $-0.49^{*}$ & 0.23 & 0.24 & 0.24 & 0.19 & -0.43 \\
\hline $\mathrm{NH}_{3}-\mathrm{N}$ & -0.12 & -0.22 & -0.37 & 0.08 & -0.25 & 0.19 & 0.25 & 0.20 & 0.22 & -0.27 \\
\hline $\mathrm{COD}_{\mathrm{Mn}}$ & -0.58 * & -0.45 & -0.24 & $-0.52 *$ & 0.17 & -0.10 & 0.26 & -0.16 & -0.04 & 0.12 \\
\hline SD & 0.02 & 0.08 & 0.13 & -0.19 & $0.54 *$ & -0.31 & $0.47^{*}$ & -0.26 & -0.32 & $0.77^{* *}$ \\
\hline DO & -0.05 & 0.10 & 0.26 & -0.32 & -0.11 & -0.20 & $0.60^{* *}$ & -0.24 & -0.21 & -0.18 \\
\hline WDP & -0.27 & -0.43 & -0.36 & -0.04 & -0.07 & 0.41 & -0.24 & 0.28 & $0.51^{*}$ & 0.05 \\
\hline $\mathrm{RW}$ & 0.15 & -0.10 & -0.09 & 0.25 & -0.26 & $0.48^{*}$ & -0.33 & $0.49^{*}$ & $0.61^{* *}$ & -0.10 \\
\hline
\end{tabular}

1) 物种与环境变量缩写的解释见表 1 、表 2 , 本表中仅列出了与水质指标显著相关的物种多度; $*$ 表示 $P<0.05$, 显著相 关; ** 表示 $P<0.01$, 极显著相关.

鱼类在春、夏季的差异, 很大程度上取决于鱼类的生活、繁殖习性; 春季水质变好也是鱼类数量增加的重 要原因,而水深降低并未影响鱼类的增加. 而空间上鱼类与主要水质指标的关系却与季节间的鱼一水质关系 不太一致. 本研究中, 龙延河样点综合水质最差, 而鱼类多度和生物量却最高; 这是因为其河道宽达 $46.7 \mathrm{~m}$ 、 水深平均达 $3.31 \mathrm{~m}$, 水流也相对湍急, 同时, 河道水向岸带 3-5 m 范围内有丰富的水生植物存在 (优势种为 挺水植物芦苇和芠草), 这些生境条件均有利于鱼类的生存和繁衍. 而综合水质相对较好的各支流, 其鱼类 
多度和生物量却小于龙延河; 支流主要分布于村落居民区, 受到生活污水排放、畜禽养殖的影响较大, 且河 道窄浅 (平均河宽 $18.2 \mathrm{~m}$, 平均水深 $1.72 \mathrm{~m}$ ), 几乎无水生植物存在, 鱼类资源量也相应偏低. 这说明在本研 究范围内,鱼类多度和生物量并非仅受到所测主要水质指标的影响, 而是同时受到河道的宽度、水深、水流 等环境条件, 以及水生植物分布状况等生境因素的综合影响, 共同决定了鱼类在不同位置的分布状况. 这些 推断尚有待于通过可控条件下的实验研究加以进一步验证.

\section{3 讨论}

河流内水文、植物群落的季节变化引起水体理化条件、河流污染状况和食物资源的相应改变, 从而对鱼 类集群产生影响 ${ }^{[8-9]}$. 研究表明水质条件对鱼类摄食的影响也表现出明显的季节变化 ${ }^{[10-11]}$. 本研究中, 春、夏 两季鱼类群落的种类数没有明显差异, 但物种组成发生了显著的变化, 2010 年春季鱼类多度明显高于 2009 年夏季, 似鳊、高体鳑鲏、麦穗鱼等种类的多度和似鳊、餐条的生物量均高于 2009 年夏季. 这是由水体污染 状况的季节变化引起的, 不同季节化肥、农药的使用强度不同, 工业污染物的排放量也发生变化, 本研究中 春季水质条件明显改善, 水体 $\mathrm{DO}$ 、透明度增加, $\mathrm{TN} 、 \mathrm{COD}_{\mathrm{Mn}}$ 降低, 使得鱼类集群多样性增加. 此外, 夏季也有 一些种类的多度及生物量比春季略高, 如刀鲚、黄䲕、翅嘴鲌、叉尾斗鱼等, 这是由这些物种的生物学特性决 定的, 夏季水温升高、一些鱼类的活力增加, 相应的样品捕获量也增加; 同时植被覆盖、人为捕捞强度、网箱 养殖密度等因素也有影响. 淡水河流水文动态、水污染状况对鱼类繁殖、生长和存活的影响是当前河流鱼类 生态学和环境生物学关注的热点问题,也是淡水鱼类保护的发展趋势.

河流内鱼类的空间分布受到微生境条件的影响, 包括水体理化特征、污染状况、河道形态等. 本研究中 测定的水体理化因子包括营养盐含量、DO、透明度等, 这些因子受到河道级别、河宽、水深等因素的影响, 对 鱼类集群发生作用 ${ }^{[2-13]}$. 在本研究水质范围内, 水体 TN、TP 等营养盐与一些种类的多度具有负相关性, 如 $\mathrm{TN}$ 浓度与似鳊、餐条多度, TP 浓度与鲫的多度都呈负相关, 这说明营养盐浓度过高会抑制某些鱼类的分布、 存活, 污染水体营养盐比例的改变可能影响鱼类集群的结构与组成, 产生的生态后果也更为复杂. 水体 DO 是决定鱼类繁殖、生长和存活的重要环境因子 ${ }^{[14]}$, 而水体透明度通过作用于鱼类视觉, 影响鱼类的捕食及繁 殖过程 ${ }^{[15-17]}$, 两者都对鱼类的群落结构、物种多样性具有重要影响 ${ }^{[17-18]}$. 本研究中, 鲫、圆尾斗鱼、叉尾斗鱼、 泥鲉、黄鳝等种类喜好栖息在透明度、DO 高的区域. 综合来看,龙延河水系的污染及相应的 DO、透明度的降 低都会对鱼类群落产生不利影响, 营养盐的大量注人致使藻类及浮游生物异常繁殖和死亡, 消耗水体 DO, 使水体长期处于缺氧状态, 有毒有害物质增加, 破坏鱼类的生存环境 ${ }^{[9,19-21]}$. 淡水生态系统内鱼类过度捕捞 与污染问题十分严重, 淡水鱼类已成为脊椎动物分类中受威胁较严重的类群之一 ${ }^{[22]}$. 近年来, 工、农业污染 物的过量排放导致河流污染形势日趋严重, 破坏了河流生态健康 ${ }^{[16]}$, 降低了河流、湖泊中鱼类的密度和物种 多样性 ${ }^{[17,23]}$. 本研究中采样得到的鱼类物种数和生物量相对都较低, 证明鱼类集群总体上面临着一定程度 的环境胁迫. 因此, 必须采取有效措施减少污染物排放、去除水体污染物、改善河道水环境, 尽快恢复和保护 已受到威胁的淡水鱼类资源.

生境多样性对于维持淡水鱼类群落的健康稳定十分重要, 通常生境结构越复杂多样, 生物多样性就越 高 ${ }^{[24]}$. 河道级别变化常伴随河道宽度、水深等生境条件的改变, 不同级别的支流河道内鱼类集群组成具有明 显差异 ${ }^{[9,18,25]}$. 本研究中, 主干支流龙延河的鱼类多度很高, 分布有刀鲚、趐嘴鲌等优势种类, 高体鳑鲏、麦穗 鱼、子陵吻虾虎鱼等种类的多度也远高于次级支流; 下场浜、岸前浜河宽较小, 其鱼类多度相应比龙延河低 一些, 但具有餐条、似鳊、鲫鱼等典型物种; 支流的末端河道窄浅、水质差, 鱼类多度很低, 仅圆尾斗鱼、麦穗 鱼有分布. 已有研究表明干流河道鱼类的物种数及多度都显著高于支流 ${ }^{[26-27]}$, 而且水体面积越大, 鱼类生物 多样性也相应越高 ${ }^{[11]}$. 龙延河河道宽达 $46.7 \mathrm{~m}$ 、水深平均达 $3.31 \mathrm{~m}$, 水流也相对湍急, 挺水植物覆盖率很 高, 是大多数鱼类重要的栖息、摄食场所; 支流河道窄浅, 几乎无水生植物存在, 因而其鱼类生物量比龙延河 低, 但支流的静水环境适合作为许多鱼类重要的繁殖产卵场所. 鱼类在不同生境的分布是鱼类生活习性对 河道各种物理环境长期适应的结果 ${ }^{[22,28]}$, 主干河道鱼类生存空间、食物资源和避难所的面积都要比支流大 一些,适合更多的鱼类栖息共存 ${ }^{[22-23,26,28-30]}$.

综上所述, 春、夏两季鱼类集群的种类数没有明显差异, 但春季捕获鱼类的多度、生物量明显高于夏季; 
主干支流、次级支流和支流末端等不同位置的鱼类组成也有一定差异. 在龙延河水系的研究表明,水体污染 引起的营养盐浓度过高和 DO 、透明度降低均对鱼类群落产生了不利影响. 以前淡水河道鱼类研究大多集中 较大尺度上的鱼类时、空变异,而关于具体环境因子与鱼类集群的明确关系的实验研究较为少见. 本研究对 水体污染的关键指标与鱼类集群的关系进行了初步探讨,阐明了鱼类不同种类的多度、生物量与 DO、透明 度以及 $N 、 P$ 营养盐浓度的基本关系, 这为下一步研究可控条件下水质关键指标 (如 $N 、 P$ 营养盐浓度) 与环 境敏感时期 (如繁殖过程和胚胎发育阶段等)鱼类变化的关系提供了基本依据. 同时,通过对太湖闸控人湖 河流直湖港小流域内鱼类资源状况的综合评价, 为直湖港水污染控制和生态修复提供了理论依据和参考 资料.

\section{4 参考文献}

[1] 倪 勇, 朱成德. 太湖鱼类志. 上海: 上海科学技术出版社, 2005: 23.

[2] 刘恩生, 刘正文, 陈伟民等. 太湖湖鲚渔获量变化与生物环境间相互关系. 湖泊科学, 2005, 17(4): 340-345.

[3] 杨再福, 赵晓祥, 李梓榕等. 太湖渔产量与水质的关系. 水利渔业, 2005, 25(3): 60-62.

[ 4 ] 刘恩生. 太湖鱼类群落变化规律、机制及其对环境影响分析. 水生态学杂志, 2009, 30(4): 8-14.

[ 5 ] 李圣法. 太湖敞水区鱼类群落结构特征的研究 [ 学位论文]. 青岛: 青岛海洋大学, 1999.

[6] 国家环境保护总局. 水和废水监测分析方法(第四版). 北京: 中国环境科学出版社, 2002: 223-285.

[7] 刘叔德, 线薇薇, 刘 栋. 春季长江口及其邻近海域鱼类浮游生物群落特征. 应用生态学报, 2008, 19(10): 2284-2292.

[ 8 ] Marchetti MP, Moyle PB. Effects of flow regime on fish assemblages in a regulated California stream. Ecological Applications, 2001, 11(2) : 530-539.

[ 9 ] Shoup DE, Wahl DH. Fish diversity and abundance in relation to interannual and lake-specific variation in abiotic characteristics of floodplain lakes of the lower Kaskaskia river, Illinois. Transactions of the American Fisheries Society, 2009, 138 (5) : 1076-1092.

[10] Xie SG, Cui YB, Zhang TL et al. The spatial pattern of the small fish community in the Biandantang Lake-a small shallow lake along the middle reach of the Yangtze River, China. Environmental Biology of Fishes, 2000, 57 (2) : 179-190.

[11] Tonn WM, Magnuson JJ. Patterns in the species composition and richness of fish assemblages in Northern Wisconsin Lakes. Ecology, 1982, 63(4) : 1149-1166.

[12] Vadas RL, Orth DJ. Habitat use of fish communities in a Virginia stream system. Environmental Biology of Fishes, 2000, 59(3) : 253-269.

[13] Bond NR, Lake PS. Characterizing fish-habitat associations in streams as the first step in ecological restoration. Austral Ecology, 2003, 28(6) : 611-621.

[14] Harris SA, Cyrus DP, Beckley LE. The larval fish assemblage in nearshore coastal waters off the St Lucia Estuary, South Africa. Estuarine Coastal and Shelf Science, 1999, 49(6) : 789-811.

[15] Rodriguez MA, Lewis WM. Structure of fish assemblages along environmental gradients in floodplain lakes of the Orinoco River. Ecological Monographs, 1997, 67(1) : 109-128.

[16] Njiru M, Mkumbo OC, Van der Knaap M. Some possible factors leading to decline in fish species in Lake Victoria. Aquatic Ecosystem Health and Management, 2010, 13(1): 3-10.

[17] Alexandre CV, Esteves KE, de Mourae Mello MAM. Analysis of fish communities along a rural-urban gradient in a neotropical stream( Piracicaba River Basin, São Paulo, Brazil). Hydrobiologia, 2010, 641(1) : 97-114.

[18] Rahel FJ. Factors structuring fish assemblages along a bog lake successional gradient. Ecology, 1984, 65 (4): 1276-1289.

[19] Baden SP, Loo LO, Pihl Let al. Effects of eutrophication on benthic communities including fish: Swedish west coast. Ambio, 1990, 19(3): 113-122.

[20] Rahel FJ, Nutzman JW. Foraging in a lethal environment: Fish predation in hypoxic waters of a stratified lake. Ecology, $1994,75(5):$ : 1246-1253.

[21] Rakocinski CF, Lyczkowski-Shultz J, Richardson SL. Ichthyoplankton assemblage structure in Mississippi Sound as revealed by canonical correspondence analysis. Estuarine Coastal and Shelf Science, 1996, 43(2) : 237-257. 
[22] Kadye WT, Moyo NAG. Stream fish assemblage and habitat structure in a tropical African River Basin( Nyagui River, Zimbabwe). African Journal of Ecology, 2008, 46: 333-340.

[23] Argentina JE, Freeman MC, Freeman BJ. The response of stream fish to local and reach-scale variation in the occurrence of a benthic aquatic macrophyte. Freshwater Biology, 2010, 55(3) : 643-653.

[24] Rodriguez MA, Winemiller KO, Lewis WM et al. The freshwater habitats, fishes, and fisheries of the Orinoco River basin. Aquatic Ecosystem Health and Management, 2007, 10(2): 140-152.

[25] Angermeier PL, Winston MR. Characterizing fish community diversity across Virginia landscapes: prerequisite for conservation. Ecological Applications, 1999, 9(1) : 335-349.

[26] Snodgrass JW, Meffe GK. Influence of beavers on stream fish assemblages: Effects of pond age and watershed position. Ecology, 1998, 79(3) : 928-942.

[27] 严云志, 占姚军, 储 玲等. 溪流大小及其空间位置对鱼类群落结构的影响. 水生生物学报, 2010, 34(5)： 1022-1030.

[28 ] Kadye WT, Magadza CHD, Moyo NAG et al. Stream fish assemblages in relation to environmental factors on a montane plateau(Nyika Plateau, Malawi). Environmental Biology of Fishes, 2008, 83(4) : 417-428.

[29] Pires DF, Pires AM, Collares-Pereira MJ et al. Variation in fish assemblages across dry-season pools in a Mediterranean stream: effects of pool morphology, physicochemical factors and spatial context. Ecology of Freshwater Fish, 2010, 19 (1) : 74-86.

[30 ] Garvey JE, Rettig JE, Stein RA et al. Scale-dependent associations among fish predation, littoral habitat, and distributions of crayfish species. Ecology, 2003, 84(12): 3339-3348. 